https://doi.org/10.48009/1_iis_2009_51-61

\title{
BUSINESS INTELLIGENCE - AT THE SPEED OF LIGHT
}

\author{
Honora M. Rockar, Robert Morris University, hmrst5@mail.rmu.edu
}

\begin{abstract}
It has been previously stated that Business Intelligence has a reciprocal relationship with Technology (delivery) and Business (information). Due to this relationship, technologies are deployed with greater speed, features, and functionality; and, business users are challenged to implement new practices faster to support strategic objectives. In addition BI, by its very nature, is an ever evolving concept defined by the competitive marketplace and leading-edge technologies. This paper, defines and explicates the notion of business intelligence, identifies some of the major players in the business intelligence arena and discusses their offerings. This paper also illustrates the computing, operational, and productivity issues facing BI as well as presents frameworks that may offer new delivery mechanisms for business intelligence.
\end{abstract}

Keywords: Business Intelligence, Data Intensive Computing, Web 2.0 and Web 3.0, Productivity

\section{INTRODUCTION}

According to Howard Dresner, Chief Strategy Officer at Hyperion Solutions Corporation, he coined the term, Business Intelligence (BI), in 1989 while he was an analyst at Gartner Incorporated, a research organization. At that time, such terms as decision support system (DDS) and executive information system (EIS) were in vogue. Dresner felt that such terminology, DSS and EIS, gave the perception that these analytical systems and their usage should be limited to upper level management. This limitation kept the analysis of vital quantitative business data from a wide range of possible users. Over its 20 year history, Dresner states that BI has evolved into what he now calls Business Process Management (BPM). Dresner believes BI has moved from purely quantitative, structured data into the realm of unstructured content as well [8].

John Zeller acknowledges Dresner's original concept was to "deliver information to end users without needing those users to be experts in operational research [14, p. 9]." This premise intimates a mutual relationship and partnership between information technology and business information, according to Zeller. However with limited resources, technology groups have been tasked to implement and support increasing numbers of applications and systems and increasing quantities of structured and unstructured data to an increasing audience of business users. And, these business users are continually being challenged to transform their organizations by identifying new business practices, defining supporting business rules, and revising standard operating procedures in support of tactical and strategic business objectives [14].

In addition, Zeller's position tends to support and update Erik Brynjolfsson's notion of the productivity paradox of information technology [1] in the sense that the paradox of business intelligence is that $\mathrm{BI}$ is an ever evolving concept driven by competition, market demands, and new technologies. As business strategies change so must business intelligence strategies change in order to support and keep pace with the needs of business organizations. Yet according to Zeller, IT groups are pressured to do more with less monitory, human, and technology resources. Increased business intelligence requires modifications to the data warehouse to include new elements to quantify the value of the new processes as well as the revised and expanded business intelligence strategies. Then, the newly adapted data warehouse elements are clearly evident within business components synchronized back to the new strategy.

These varied components and users of business intelligence are illustrated in an Aberdeen Group report and the visual below, showing the position of the business user, the analysts, and the technology specialists. The report goes on to identify that the best in class organizations have high confidence in their data for daily decision-making; have the ability to use data extracted from systems without manual manipulation or scrubbing; have a plan within a year to set up an environment that will enable them to drill down to transactional detail directly from summary data; and empower users to establish their own views of data. In addition, best in class organizations communicate corporate goals and establish metrics to measure progress towards these goals; implement triggers and alerts to sense changes in performance and notify decision-makers so that action can be taken immediately rather than days, weeks or 
months; and implement dashboards or portals that facilitate drilling down to transactions from summarized data [12].

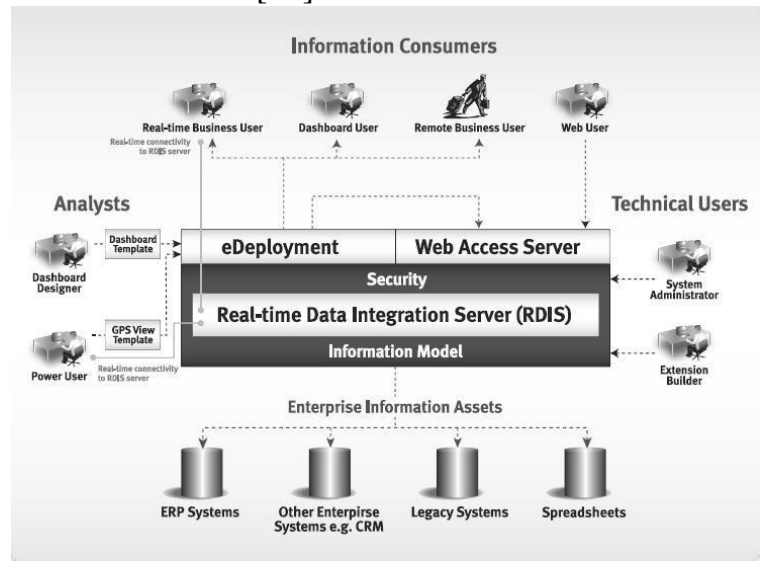

Business Intelligence: Systems and Users [12]

In this paper, I will further define and explicate the notion of business intelligence, identify the major players in the business intelligence arena and discuss their offerings, illustrate the computing, operational, and productivity issues facing BI as well as present frameworks that may offer new delivery mechanisms for business intelligence.

\section{Discussion}

History and Definition. Even though Howard Dresner claims he created the term, business intelligence, this activity was carried out in some way in organizations as far back as circa 8,000 BC with Neolithic clay tokens being used as a means to keep account of agricultural and other surpluses. Cuneiform tablets then refined the economic accounting role of these tokens and eventually led to the invention of cuneiform writing [5]. Similarly, because of this historical need of mankind to create an understanding of current situations in order to be proactive about the future, business intelligence inherently incorporates many technical elements and crosses over many informational boundaries, including marketing and sales, product development, legal, accounting and finance, and customer support. This inclusiveness also illustrates the problems with ownership and control. However, this inclusiveness and need to know also brings about an even broader taxonomy of terms for business intelligence, for example, competitive intelligence and millennium intelligence are just some of the all encompassing terms used to expand the notion of business intelligence and its market. Business, competitive, and millennium intelligence can be defined as "the process of ethically collecting, analyzing, and disseminating accurate, relevant, specific, timely, foresighted, and actionable intelligence regarding the implications of the business environment, competitors, and the organization itself' in the digital age [4].

Computing, Operational, and Productivity Issues. When we think of computational issues, we must consider the vast and interdisciplinary field of business intelligence as described above. And, we must realize that the dependent computational routines include, but are not limited to, several related activities such as data mining, online analytical processing (OLAP), querying, and reporting. Failure in any one of these areas might cause losses for an organization because BI is used by the organization to identify and uncover new business opportunities, improve decision making, cut costs, pull enterprise resource planning (ERP) information into accessible reports, react quickly to customer demands and optimize product prices. BI is also used to identify inefficient business processes, quantify the value of relationships with suppliers and customers in the supply chain cycle, and improve relationships. Therefore, the data feeding into BI applications should be clean and consistent in order to get these benefits out of the applications.

For example, Amazon.com and CDW.com are not just ecommerce sites but are extremely analytical sites that follow a dynamic approach to changes in their business. Wal-Mart uses large amounts of data and category analysis to dominate their retail industry. In these organizations, employees modify their individual and teamwork practices that create improved performance by using BI systems. However while implementing business intelligence applications and systems, these companies and all companies must first analyze the way they make decisions and consider the information that is required to support that decision making. In addition in order for BI technology systems to work effectively, companies need to have secure computer operations that specify levels of user access to the data warehouse. In addition, the BI system needs to have sufficient data capacity and a plan for how data storage and retention. Business analysts must set benchmarks and performance targets for the BI system. If these benchmarks and targets are not 
reached, changes must be made to the systems. Traditionally, the tools for accessing large amounts of unstructured data for the purpose of analysis were available only to people with years of experience in data warehousing or data mining. Publishing to the web by using data from multiple sources is something historically restricted to developers and consultants. But with current BI applications and systems, properly implemented, these capabilities are now provided to more levels of business intelligence users [10].

Supporting the above computing discussion, Dayal, et. al., in their 2009 article, state business intelligence is at a turning point today. Dayal argues organizations have traditionally used BI for offline, strategic decision-making. Following this offline method, a small number of expert users analyze historical data and decision-making cycles over weeks or months. As organizations become more automated, real-time, and data-driven, the industry is evolving toward adaptive operational BI systems that support online, operational decision making at all levels in the organization. Daval, et. al., provide examples of online retailers who analyze users' realtime click stream data and review up-to-the minute inventory to offer dynamically priced product bundles as well as banks detecting and reacting to fraudulent credit card transactions. Their position is that as data warehouses grow bigger and queries become more complex, managing the duration, CPU cycles required, and disk I/O tasks will become more difficult. That is existing systems will be unable to support these data stores and query requirements so that the information returned may be incomplete or incorrect, negatively affecting decisions. In order to correct this situation, they propose an effective workload management system that can identify and handle long-running queries and provide workload management actions not only to admission control and scheduling but also to kill, kill and requeue, or suspend and resume queries. Their work complements query progress indicators that attempt to estimate a running query's degree of completion before the workload has been negatively impacted. In order to do so, Dayal, et. al., carried out a systematic study of workload management policies intended to limit the impact of inaccurate information. They also develop techniques for predicting multiple-query resource requirements of both short and long running queries more accurately, hoping to improve the effectiveness of critical tasks that rely on accurate

Volume X, No. 1, 2009 predictions, including system sizing, capacity planning, and workload management [2].

In terms of productivity, the Aberdeen Group reviewed the benefits of business intelligence with regard to productivity and found that 23 percent of leading retailers such as Wal-Mart, Staples, and Best Buy have already adopted an enterprise-wide BI strategy defined as the ability to access information affecting the entire business as the data is created.

Aberdeen found that there were difficulties in implementing and maintaining enterprise-wide BI related to data integration, cleanliness, and alignment of business processes to the metrics that drive effective planning and decision-making at the corporate network, stores, and other channels. However, those organizations who were Best-inClass in terms of enterprise-wide BI outperformed their competitors and were ultimately more productive in terms of process, knowledge, technology, and overall performance [12].

\begin{tabular}{|c|c|c|c|}
\hline & Best-in-Class & Average & Laggards \\
\hline \multirow{4}{*}{ Process } & \multicolumn{3}{|c|}{$\begin{array}{l}\text { Ability to segment customers based on purchase behavior and } \\
\text { affinity }\end{array}$} \\
\hline & $61 \%$ & $45 \%$ & $35 \%$ \\
\hline & \multicolumn{3}{|c|}{ Ability to generate automated reports } \\
\hline & $76 \%$ & $66 \%$ & $53 \%$ \\
\hline \multirow{2}{*}{ Organization } & \multicolumn{3}{|c|}{ Develop reporting process based on job role } \\
\hline & $53 \%$ & $30 \%$ & $17 \%$ \\
\hline \multirow{4}{*}{ Knowledge } & \multicolumn{3}{|c|}{ Ability to collect, integrate and analyze customer data } \\
\hline & $63 \%$ & $46 \%$ & $35 \%$ \\
\hline & \multicolumn{3}{|c|}{ The ability to define KFIs that are relevant to the business } \\
\hline & $67 \%$ & $50 \%$ & $48 \%$ \\
\hline \multirow[b]{2}{*}{ Technology } & \multicolumn{3}{|c|}{$\begin{array}{l}\text { Applications or platforms that can support the use and } \\
\text { acceptance of } \mathrm{Bl} \text { in retail }\end{array}$} \\
\hline & $\begin{array}{l}\text { - } 72 \% \text { enterprise } \\
\text { data warehouse } \\
\text { - } 61 \% \text { operational } \\
\text { dashboards } \\
\text { - } 56 \% \text { scorecards } \\
\text { - } 46 \% \text { data } \\
\text { cleansing } \\
\text { software } \\
\text { application } \\
\text { - } 43 \% \text { web analytics } \\
\text { - 35\% end-to- end } \\
\text { bi application } \\
\text { suite }\end{array}$ & $\begin{array}{l}\text { - } 43 \% \text { enterprise } \\
\text { data warehouse } \\
\text { - } 54 \% \text { operational } \\
\text { dashboards } \\
\text { - } 43 \% \text { scorecards } \\
\text { - } 35 \% \text { data } \\
\text { cleansing software } \\
\text { application } \\
\text { - } 39 \% \text { web analytics } \\
\text { - } 26 \% \text { end-to-end } \\
\text { bi application } \\
\text { suite }\end{array}$ & $\begin{array}{l}\text { - } 36 \% \text { enterprise } \\
\text { data warehouse } \\
-36 \% \text { operational } \\
\text { dashboards } \\
-36 \% \text { scorecards } \\
-22 \% \text { data } \\
\text { cleansing software } \\
\text { application } \\
-21 \% \text { web analycics } \\
-15 \% \text { end-to- end } \\
\text { bi application } \\
\text { suite }\end{array}$ \\
\hline \multirow[b]{2}{*}{ Performance } & \multicolumn{3}{|c|}{ Performance management parameters used: } \\
\hline & $\begin{array}{l}\text { - } 67 \% \text { provide } \\
\text { store-level } \\
\text { performance data } \\
\text { - } 50 \% \text { establish } \\
\text { performance } \\
\text { thresholds for } \\
\text { business } \\
\text { improvements } \\
\text { - } 50 \% \text { provide } \\
\text { performance data } \\
\text { at the associate } \\
\text { level }\end{array}$ & $\begin{array}{l}\text { - } 54 \% \text { provide } \\
\text { store-level } \\
\text { performance data } \\
\text { - } 39 \% \text { establish } \\
\text { performance } \\
\text { thresholds for } \\
\text { business } \\
\text { improvements } \\
\text { - } 32 \% \text { provide } \\
\text { performance data } \\
\text { at the associate } \\
\text { level }\end{array}$ & $\begin{array}{l}\text { - } 43 \% \text { provide } \\
\text { store-level } \\
\text { performance data } \\
\text { - } 37 \% \text { establish } \\
\text { performance } \\
\text { thresholds for } \\
\text { business } \\
\text { improvements } \\
\text { - } 24 \% \text { provide } \\
\text { performance data } \\
\text { at the associate } \\
\text { level }\end{array}$ \\
\hline
\end{tabular}

BI: Use and Maturity in Retail [12] 
Even though Zeller echos the concern of Brynjolfsson of information technology and the productivity paradox with regard to business intelligence, it appears that the benefits exist at least in terms of retail businesses.

Web 2.0, Web 3.0, Data Intensive Computing. During 2007, press releases and customer contacts indicated that analytic applications vendors were merging with customer intelligence, customer relationship management (CRM), and Enterprise Resource Planning (ERP) providers. If organizations are not privy to aware of the changes in their corporate landscape, they may lose ground when it comes to competition in the marketplace. The convergence of $\mathrm{BI}$ and the Internet is proving to be the critical next step to supplying company infrastructures with the decision-making and web capabilities they need to move forward in ecommerce. In considering BI, organizations can leverage their investments by pulling information from that system into a separate, well organized structure from which beneficial decisions can be drawn. This vital information enables these organizations to leverage their website with their existing data warehouse to create the overall infrastructure needed to support and supply BI information for their other initiatives. Organizations must constantly gather current information about their competitors to win the race. These web-enabled applications are used to collect data daily and store the information in a data warehouse [11].

In support of these enterprise-wide business intelligence initiatives, we must also look at Web 2.0 technologies and their incorporation of social network applications, including blogs, mash-ups, really simple syndication (RSS) feeds, tagging, and wikis. The information gathered from these external and internal sources will eventually lead to changes in business intelligence applications and systems. The understanding is that early adopters have focused their efforts on the creation of online communities to gather information relating to product marketing or development of new products. Going forward, these organizations will implement Web 2.0 to interact better with their customers and employees [13].

As can be seen from the visual below, Web 3.0 ties together even more data types, using Semantic Web technologies and graph-based, open data. This functionality is supported by the Resource Description Framework (RDF). RDF enables the linking of data from multiple websites or databases. The RDF schema and the Web Ontology Language (OWL) provide the ability to infer relationships between data in different applications or parts of the same application [3]. This additional functionality will eventually affect business intelligence application offerings.

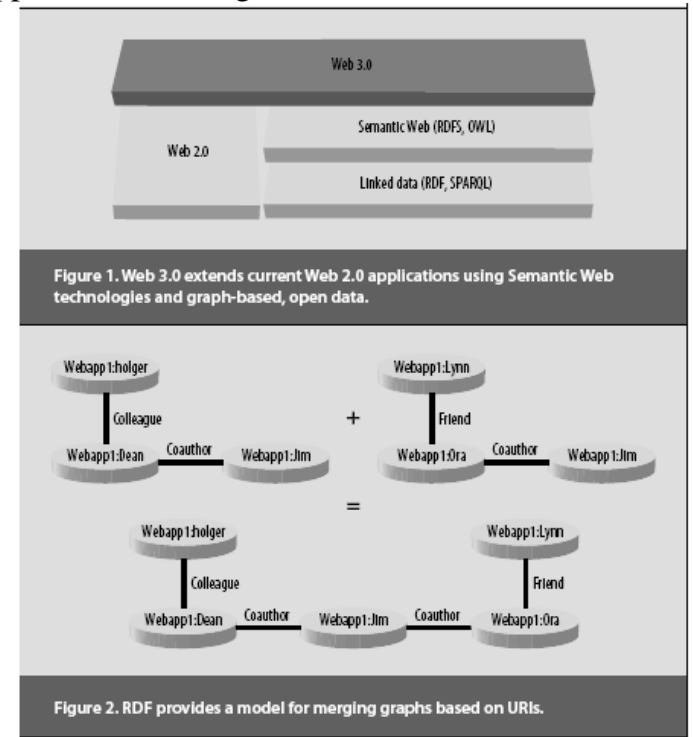

Web 3.0 Emerging [3]

With regard to Web 2.0 and Web 3.0, we must also consider data intensive computing requirements and their relationship to business intelligence applications. Power grids, climate models, genomics, social networking sites, intelligence communities, high-energy physics generate more and more raw data. For example, Google sifts through 20 petabytes of data per day. According to Kouzes, "data-intensive computing could be qualitatively defined as any computational task where data availability is the ratelimiting factor to producing time-critical solutions. 


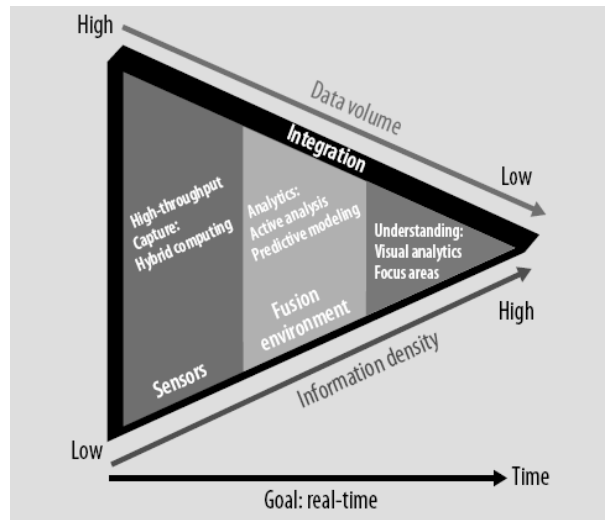

Changing Paradigm Data-Intensive Comp [6]

Data-intensive computing is managing, analyzing, and understanding data at volumes and rates that push the frontiers of current technologies. Data intensive computing requires new classes of software, algorithms, and hardware [6, p. 28]."

Trends and Products. According to a recent KMWorld article, business intelligence thrives in touch economic times almost as well as it does in good economic times. The article cited a survey conducted with information technology and business leaders throughout Europe, China, and the United States by AMR Research. The survey indicated that the global market for BI applications will be $\$ 57.1$ billion in 2008. The United States market alone was predicted to total $\$ 25.5$ billion. While the growth rate was expected to be somewhat slower than in the past, at about 5 percent, there was an expected increase over the next several years. The report indicated that some of the resiliency in the business intelligence marketplace came from the fact that organizations must understand what's happening whether their markets are rising or falling. During a strong economy, BI is normally called upon to guide business expansions; however, in a tight economy, BI is called upon to facilitate cost savings or enable cost cutting [7].

With the above BI market summary in mind, this discussion turns to business intelligence products. The discussion draws from the KMWorld Buyers' Guide, Fall 2008 Edition and its Index to Research Centers. I've selected several of those companies that indicate they represent Business Intelligence (BI), Business Process Management (BPM), and/or Competitive Intelligence (CI) as their primary product offerings. I intend to review market and product information listed on each organization's

Volume X, No. 1, 2009 website and determine the extent to which their product offerings support the claims of providing BI, PBM, or CI software applications. In addition, I'll determine if their products follow the trend to Web 2.0 social networking and Web 3.0 semantic application solutions. Drawing from the Knowledge Management Buyers' Guide, six organizations were identified for analysis and discussion. Those organizations are as listed in Table 1 below.

\begin{tabular}{|l|l|l|}
\hline Organization & Organization & Organization \\
\hline $\begin{array}{l}\text { 5280 Solutions, } \\
\text { Inc. }\end{array}$ & EXSYS, Inc. & Global 360 \\
\hline $\begin{array}{l}\text { Hewlett- } \\
\text { Packard }\end{array}$ & InMagic, Inc. & InQuira Inc. \\
\hline $\begin{array}{l}\text { Soffront } \\
\text { Software, Inc. }\end{array}$ & & Oracle, Inc. \\
\hline \multicolumn{2}{|l|}{ Table 1: BI Organizations } \\
\hline
\end{tabular}

5280 Solutions, Inc. (Focus: Business Intelligence in Finance for Educational Institutions)

Since 1980, 5280 Solutions, Inc. has been located in Highlands Ranch, CO. Even though 5280 Solutions is listed in the Research Center as providing business intelligence and business process management, their focus appears to be on educational lending software solutions, enterprise content management, and customized software solutions. The software developed by 5280 Solutions focuses on the needs of higher education and financial service organizations. According to 5280 Solutions, their software has been implemented in dozens of financial institutions across the United States, Canada, and in Europe. These groups manage about $\$ 80$ billion worth of educational loan assets. Their customers look for an integrated solution to assist them with document, imaging, records, and workflow management. The software solutions must be simple to implement, requiring little or no programming or specific technical knowledge. 5280 Solutions packaged software includes Dynamic Payables, Dynamic Filer, and Uconnect.

Dynamic Payables (DP) is an integrated accounts payable application that provides advanced automation and workflow for invoice processing. This application integrates with existing accounts payable applications. DP matches invoices to purchase orders, follows general ledger coding, provides review and approval processes, and integrates with existing accounts payable software, bridging the gap between paper and electronic

$55 \quad$ Issues in Information Systems 
processing. DP works with Microsoft SharePoint Server 2007 and Windows Workflow Foundation. In addition, DP provides document-capturing technologies to increase productivity, accuracy, and maintain service levels without additional staff.

Dynamic Filer (DF) automates the process of scanning and filing paper documents into SharePoint as well as searching for electronic documents and scanned images directly from existing business applications. DF allows users to link and search for scanned documents from their business systems.

Uconnect is an integrated software application that is designed to communicate with most Windows, Webbased, or hosted applications, as well as data structures such as eXtensible Markup Language (XML). Uconnect connects to and integrates with other applications, workflow systems, document management repositories, and data structures.

5280 Solutions focuses upon educational lending institutions and can claim to provide business intelligence software because of Uconnect, which enables users to communicate with data and document management repositories. The assumption is that the other linking applications provide the dashboard into and reporting of the data. It appears that 5280 Solutions is attempting to keep its applications current with technologies but does not take a leading role into Web 2.0 or extreme data intensive requirements in that its customers, as educational lenders, do not have these specific needs.

EXSYS, Inc. (Focus: Business Process Management) Interestingly, for over 25 years, EXSYS, Incorporated, has been located in Albuquerque, NM, which is not necessarily the hot bed of high technology startups. The focus of Exsys and its software is to gather the knowledge in companies that might be lost due to employees retiring or changing jobs. Exsys market position is that experienced employees may have vast amounts of tacit knowledge, which the company relies on, but that knowledge can be lost when employees leave the organization. Their primary product, Corvid, captures the tacit knowledge of experts and their decisionmaking processes for a subject. This method provides detailed documentation of the knowledge that can be reviewed and interpreted and then automatically

Volume X, No. 1, 2009 builds an online system, enabling that knowledge to be used whenever needed.

According to Exsys, Corvid provides the best method to systematically capture structured decision-making logic of organizational experts. Those experts describe the way they approach problems, and the Corvid system follows and records their methodology. Corvid uses structures called, Logic Blocks, that allow the system to parallel the expert's decision-making process. By automatically indicating where the logic has gaps, Corvid indicates so the expert's methodology can be filled in completely and systematically. The logic can be immediately tested to evaluate if the expert agrees with the results. Then the logic is re-examined to determine where expansion or correction is required. Once complete, the Corvid system can be implemented on the Web to provide an interaction with end users that emulates a conversation with the expert to provide situationspecific advice. With Corvid experts can build their own knowledge automation system or work with someone trained in Exsys Corvid to rapidly build systems that capture and preserve their knowledge on particular tasks. Exsys claims that if Corvid is implemented throughout an organization, the derived repository of business knowledge not only preserves business knowledge but also automatically delivers that knowledge online via the Exsys Corvid Inference Engine.

Exsys claims to provide business intelligence, business process management, collaboration, competitive intelligence, content management, and customer relationship management. However, the focus seems to be the collection of tacit knowledge rather than the mining of existing structured or unstructured data.

Global 360 (Focus: 360 View of the Customer through Business Intelligence)

From Dallas, TX, Global 360 provides software solutions to organizations that must automate, measure, optimize, and improve resource-intensive business processes across stakeholders, including customers, employees, and partners. Its enterpriselevel solutions facilitates human- or document-centric business process management suite, or focuses on specific business requirements, including end-to-end document lifecycle management, collaborative case management, or feature-rich imaging capabilities. 
Business Process Management. As was stated above, the notion of business intelligence moved into the notion of business process management, providing a more encompassing perspective or nomenclature of data mining and intelligence operations. Global 360's offering for business process management is Process360 that enables organizations to create, execute, and optimize business processes. Accordingly the product claims to manage processes through their entire lifecycle, to shorten process lifecycles, and to manage process exceptions.

Complete Process Lifecycle Management for Content, Work, and Processes. For a process application that provides capture, imaging, content, and work management, Global 360 offers Execute360. Execute360 manages process lifecycles, automating mission-critical applications and optimizing business processes. Execute 360 enables organizations to integrate content with business applications to manage information gathering and business processes for improved business responsiveness and operational efficiency.

Collaborative Case, Content and Process Management. The Case 360 product joins the capabilities of collaborative content and business process management applications into one application. Case 360 gives organizations a view into and control over their documents and electronic information as well as the processes that governs those items. Case 360 is a tool that focuses on the needs of collaborative teams and their environments, facilitating access to documents, tasks, deadlines, alerts, and threaded discussions from within a virtual folder that Global 360 calls a casefolder. The Casefolder holds the information necessary to develop a case. The folder can be accessed by all in the organization, but is restricted according to roles and privileges. The intent is to provide an integrated view of the data so that the organization has access to yet control over its data and operations. According to Global 360, their portfolio of Work Management solutions provide comprehensive information and document management as well as process management tools for organizations that need to optimize, automate, and enhance their operations. Global 360's Information Management products are said to provide document capture capabilities supporting multiple scanning stations in centralized or distributed mailroom configurations, manage

Volume X, No. 1, 2009 reports, and integrate core data into business processes. This method is to maintain compliance through automated records management. Global 360 Imaging for Windows scans paper documents into electronic files that can be viewed, edited through optical character recognition (OCR), emailed, uploaded or downloaded from a website.

Through Global 360, we see the marketing notion of a 360 degrees view of the customer. Here, the intimation is that their products allow the total collection, storage, configuration, and distribution of data that provides a complete view of the organization and its stakeholders. We see Global 360 taking Dresner's notion of placing data not only into the hands of top-level executives but to all those throughout the organization.

Hewlett-Packard (Focus: Hardware along with Software for Business Intelligence)

Located in Palo Alto, CA, Hewlett-Packard claims to provide business intelligence products for all industries whether those industries are media, financial services, health or life sciences, or retail and consumer products. HP states that its products cover business information management solutions, business information solutions; data warehouse, server, storage, and virtualization solutions; the Neoview enterprise data warehouse solution as well as storage area network (SAN) products.

It appears that HP is trying to leverage its hardware product line by adding business intelligence software solutions so that customers have a one-stop-shop to its data storage and access needs. HP claims that the most important element for organizations when it comes to business intelligence is to ensure that the business intelligence environment is constantly available. If the organization disparate management systems and limited resources to monitor and manage its availability, all the data is really of no use to the organization. HP offers its specialized software products that manage end-to-end business intelligence and data warehousing processes. For example, HP Systems Insight Manager is meant to increase uptime by providing monitoring and control tools, HP Serviceguard provides scalable, clustered environments, HP Database Archiving software is meant to facilitate the movement of inactive data from online storage to a storage subsystem, HP Business Technology Optimization software is said to provide a single, unified view of an organization's

Issues in Information Systems 
IT infrastructure as well as the data that within the infrastructure.

HP Process Aware Business Intelligence (PABI) solutions claim to enable the integration of business analytics into the workflow of business applications; while HP virtualization solutions provide the flexibility to redistribute processing power pooling and sharing resources. With Hewlett-Packard, we see how a company with a focus on hardware positions itself into the business intelligence, business process management, collaboration, and content management arena. HP would be the primary source for those organizations looking for data-intensive computing solutions as discussed above by Kouzes.

InMagic, Inc. (Focus: Social Business Intelligence for Corporate Libraries)

InMagic's primary offering is Presto, which claims to focus on the needs of Information and Knowledge Management professionals who must manage secure information through social network systems. Located in Woburn, MA, InMagic provides Presto for Social Libraries to manage collections and library archives with the benefit of collaboration. This product organizes an organization's documents, drawings, spreadsheets, blogs, images, videos, and really simple syndication (RSS) feeds into a single data location.

According to InMagic, Presto enables a community of practice by enhancing the organization's ability to share and capture its tacit knowledge. By implementing its secure, content-centric, social technologies, InMagic claims that it facilitates an organizations ability to search and discover across multiple data sources. In addition, InMagic's provides workgroup tools and publishing capabilities for an integrated library automation system (ILS) called Genie. This product is a Web-based system with information management tools. The technology is designed manage access to both traditional and nontraditional library materials. In addition, InMagic provides an interactive Web publishing and access system that allows users to deploy, publish, and maintain content on the Web. And, InMagic offers a database and text retrieval system that enables users to build networked and standalone content, managing different types of information: documents, images, and multimedia. A Library Automation workflow system through a simple web-based interface brings web publishing capabilities to traditional textbases.
This capability allows for cataloging, organizing, and publishing unstructured documents. InMagic focuses on information centers that must manage and provide effective access to both traditional and nontraditional library materials.

Here we see the incorporation of Web 2.0 social network and Web 3.0 methodologies with a target market of corporate libraries, that is, those organizations that provide informational Intranets to facilitate their employees work and decision-making. Again, we see Dresner's notion of bringing the decision making ability to all levels of the organization through information access.

InQuira Inc. (Focus: Semantic Search and Knowledge Management)

Founded in 2002 and located in San Bruno, CA, InQuira offers a platform that features integrated semantic search and knowledge management capabilities. With InQuira's enterprise software, organizations can develop the quality content, ensure the content is accessible, and provide a customer experience that advances business objectives. InQuira provides a platform that has three core capabilities: knowledge base management with the ability to author and manage workflow, semantic search, and advanced analytics and reporting. InQuira products claim to enable organizations to deliver a superior experience to their customers through the Web and through agents in contact centers. Their products identify and develop the content required for each customer situation and deliver the content when required. InQuira Intelligent Search. This product combines advanced linguistic techniques and contextual understanding to provide semantic search capabilities, enabling organizations to understand and respond to the true intent behind a user's inquiry and browsing behavior. InQuira Information Manager. This product is a comprehensive knowledge management system for identifying, developing, organizing, and sharing enterprise information. InQuira Analytics. This product is a reporting package that delivers the insights organizations need to manage the user experience on the Web and in contact centers by continuously refining self-service and online marketing interactions, and enhance the ongoing capture, organization, and retrieval of content. InQuira products enable organizations to form information repositories and provide comprehensive information access. The analytics 
enable customers to optimize their knowledge management and customer service processes. Their products delivered more effective online support that boosted customer satisfaction, increased call deflection, and lowered support costs. Harnessed knowledge management capabilities streamline content development, aggregation, and sharing which leverage corporate knowledge across the enterprise.

Here we see how business intelligence is defined as a support device for customer service, either through direct customer contact or by allowing the customer to search knowledge bases on the organization's website.

Soffront Software, Inc. (Focus: Knowledge Management for Customer Support)

Founded 1992 in Milpitas, CA, Soffront's primary product, Knowledge Management System (KMS), provides access to product and business knowledge of an organization to its customers. KMS supports help desk, marketing and sales, and all areas of organizations to learn the value of aggregating and providing access to collective business memory. Soffront KMS with Soffront Customer Relationship Management (CRM) helps companies automate customer interaction, supply answers to customer facing employees, and uncover new business opportunities for the organization. KMS gives employees access to the knowledge gained throughout an organization, aggregating employee knowledge about business practices, products, and customers. This methodology can illustrate ways to become more productive. KMS is a web-based, selfhelp knowledge management software product. The product provides knowledge base and self-help to customers, partners, and employees. KMS enables building and sharing knowledge, which can be leveraged for sales, marketing, customer support, employee support and defect tracking applications. This interface can be a part of the Soffront CRM Portal or any Intranet/Extranet. With Soffront, we find that business intelligence equates to knowledge management for customer support. Here, knowledge management is conducted to support customer relationship management whether through help desk support or defect tracking and automatic email responses.

Oracle (Focus: Total Marketplace)

Oracle Corporation was founded in 1977 in Redwood City, CA. In 2008, Oracle had over $\$ 22$ billion in revenue. The company first focused on database

Volume X, No. 1, 2009 products. Presently, to maintain its market dominance with Microsoft and other competitors, Oracle offers total enterprise-wide software solutions, including business intelligence, which falls in its middleware area. Its applications support all areas of enterprisewide requirements in resource management, accounting and finance, support. Oracle Business Intelligence is part of the Oracle Fusion Middleware offerings which provide the business intelligence and analytic capabilities based on Oracle's products for online analytical processing (OLAP) interactive dashboards, analysis, detection and alerts, reporting and publishing, mobile analytics, and desktop gadgets.

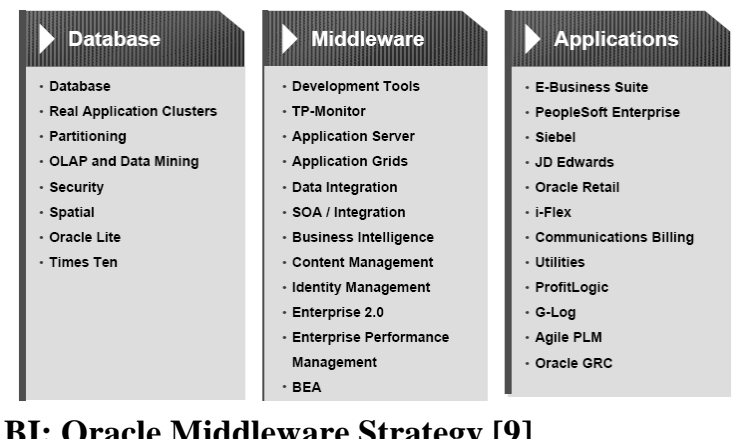

\section{BI: Oracle Middleware Strategy [9]}

Following Dresner's position, Oracle's business intelligence products claim to deliver intuitive, rolebased intelligence for everyone in an organization, including front line employees through senior management to enable better decisions, actions, and business processes. Their products integrate information and financial performance management, operational intelligence, and transactional applications, using existing data sources and systems. Oracle BI products are hot-pluggable with Oracle and non-Oracle environments, meaning the applications can be switched without taking down operations or performing programming changes. Oracle also provides products for business process management (BPM) and business process automation (BPA) through a pre-integrated portfolio of products that include modeling tools for business analysts, developer tools for system integration, business activity monitoring for dashboards, and user interaction for process participants.

Issues in Information Systems 


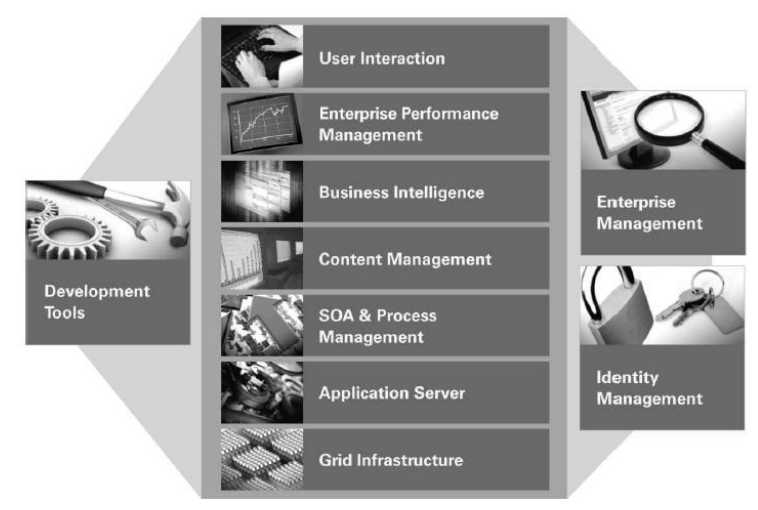

BI: Oracle Middleware Strategy [9]

Oracle Business Process Management (BMP) Suite and Oracle Business Process Automation (BPA) Suite are meant to drive customer service and operations, which also provide business value to service oriented architecture (SOA). Oracle BPM Suite is Oracle Fusion Middleware's strategic product for BPM, combining BPM from Oracle with BEA systems. As can be seen from the visual below, Oracle's products are meant to provide the necessary data to everyone, anywhere, and any time through web portals, to desktops, and mobile devices.

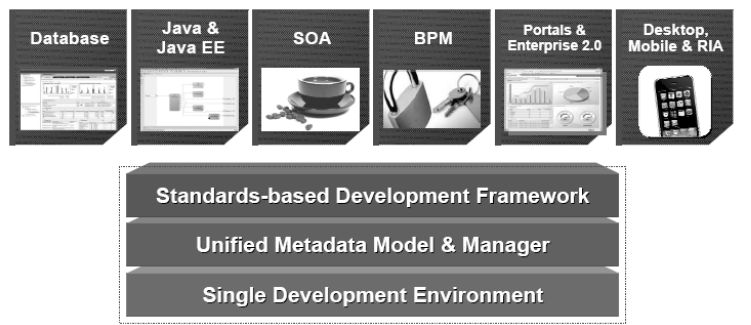

BI: Oracle Middleware Strategy [9]

\section{CONCLUSION}

As Dresner suggested and Zeller reinforced, corporations providing decision systems broadened their approach from Decision Support Systems and Executive Information Systems to Business Intelligence and then on to Business Process Management and/or Competitive Intelligence. This movement not only opened access of corporate data to a wide range of possible users based on their role with the organization but also increased the sales potential of those providing the BI applications. By just reframing their products concept, while maintaining a modicum of security and control, organizations such as Oracle, increased market potential. However, not all organization or their products are equal when it comes to business intelligence software providers.

Providers, such as 5280 Solutions, focus on a single market, educational lending institutions, and provide intelligence gathering applications to coordinate, monitor, and analyze their lending activities. Exsys focuses its products on gathering the tacit knowledge from individuals within organizations and defines the processes that enable their implementation. Exsys products collect tacit knowledge rather than the mining existing structured or unstructured data. Ensys delivers this knowledge through web-based applications.

Global 360 takes a 360 degree approach with its products and marketing approach. Global 360 provides most focused line of business intelligence products, support business and competitive intelligence, business process management, document, content, imaging, and lifecycle management. Whereas, Hewlett-Packard uses its business intelligence applications to further its sale of hardware. HP's data warehouse solutions are tied to its server and networking hardware.

InMagic and InQuira target their markets with InMagic focusing on content management for corporate libraries and Intranets; and InQuira focusing on semantic search, knowledge management, and analytics. Soffront focuses its business intelligence applications in the area of knowledge management fur customer support; while Oracle attempts to be everything to everyone in terms of business intelligence through its product offerings and acquisitions of BEA, PeopleSoft, and Hyperion. BEA Systems, Inc., a leading provider of enterprise application infrastructure solutions. BEA provides service-oriented architecture (SOA) infrastructure and business process management for Web 2.0 applications, including customer relationship management, enterprise performance management, asset management, supply chain management, and financial management. Oracles breath of operation is meant to compete directly with Microsoft.

Through this selection of business intelligence providers, we can see how technology defines and drives the marketplace and yet is, in turn, defined and driven by the requirements of the marketplace. While broadening the definition of decision-support and 
executive-support systems to business intelligence and business process management, this reframing increased data, its permutations, and access requirements to far reaching levels and new ways of access and speeds - at the speed of light.

\section{REFERENCES}

1. Brynjolfsson, E. (1993). The Productivity Paradox of Information Technology. Communications of the Association for Computing Machinery, 36(12), 67-77.

2. Dayal, U., Kuno, H., Wiener, J. L., Wilkinson, K., et al. (2009). Managing Operational Business Intelligence Workloads. SIGOPS Operating Systems Review, 43(1), 92-98.

3. Hendler, J. (2009, January). Web 3.0 Emerging. IEEE Computer, 88 - 90.

4. Hogan, T., \& Sochacki, S. (2000). Millennium Intelligence: Understanding and Conducting Competitive Intelligence in the Digital Age. Retrieved 28 February 2009, 2009, from http://www.infotoday.com/pressreleases/pr00030 1-4.htm.

5. Justus, C. F. (2002). Ancestor of the West. Writing, Reasoning, and Religion in Mesopotamia, Elam, and Greece. Visible Language, 36(1), 62 - 74.

6. Kouzes, R. T., Anderson, G. A., Elbert, S. T., Gorton, I., et al. (2009, January). The Changing Paradigm of Data-Intensive Computing. IEEE Computer, 26 - 34.

7. Lamont, J. (2008, September). BI, In Good Times and Bad. KMWorld, 17, 14 -15.

8. Martens, C. (2006). Business Intelligence at Age 17. Retrieved 28 February 2009, from http://www.computerworld.com/action/article.do ?command=viewArticleBasic\&articleId=26629.

9. Phillips, C. (2008). Your. Open. World. Retrieved 28 February 2009, from http://www. oracle.com

10. Saha, G. K. (2007). Business Intelligence Computing Issues. Ubiquity, 8(25), 1 - 6.

11. Unknown. (2007a). The Guide to CRM Automation (15th ed.). Bethesda, MD: ISM, Inc.

12. Unknown. (2007b). Intelligent Performance Management: Aligning Day-to-Day Decisions to Meet Corporate Goals. Retrieved June, from www.aberdeen.com

Volume X, No. 1, 2009
13. Unknown. (2009). Serious Business: Web 2.0 Goes Corporate. The Economist Intelligence Unit, 1 - 19.

14. Zeller, J. J. (2007). Business Intelligence: The Chicken or The Egg. Business Intelligence Review, 3(2), 9 - 12. 